\title{
Educação a distância: uma investigação sobre possíveis contribuições para a educação continuada de professores de língua estrangeira (Inglês)
}

Edimara Sandra Camarota Queiroz

Universidade Federal de Uberlândia

Este estudo teve por objetivo apresentar algumas contribuições da Educação a Distância para a educação continuada de professores de língua estrangeira (inglês), no processo de ensino/aprendizagem de língua estrangeira mediado pela tecnologia. Os recursos oferecidos pela tecnologia são relevantes para a EAD no sentido de que possibilitam a ampliação de novas oportunidades de aprendizagem, principalmente para aqueles aprendizes que, por diversas razões, outrora, não podiam dar seguimento a seus estudos pelo método presencial. O uso de tecnologia, mais especificamente a Internet, possibilita ao aprendiz o acesso à informação que pode auxiliá-lo no processo de construção do conhecimento, tornando-o sujeito ativo no seu processo de formação.

The aim of this paper is to show some possible contributions of Distance Education in a new perspective of teaching/learning processes of a Foreign Language supported by technology. The resources offered by technology are very important and they make it possible to amplify new learning opportunities for those students who, for many reasons, cannot continue their learning process through the presence mode. The use of technology, more specifically the Internet, allows the access to information which may help the students to build their knowledge and become themselves active in their learning process.

\section{Introdução}

Visando à difusão e à democratização da informação e à construção do conhecimento, surge a tecnologia como uma possível mediadora na construção de uma nova representação da sociedade.

Sabemos que, hoje, vivemos em um mundo globalizado em que as instituições educativas vivem uma crise geral de identidade. Com isso, somos levados a pensar em processos educativos além das instituições de ensino mais tradicionais, para que a relação presencial 
professor/aluno possa ser transcendida e o formalismo acadêmico possa, também, ser revisto.

Assim, ampliam-se as possibilidades de novos ambientes de aprendizagem onde aprendizes, muitas vezes excluídos das instituições presenciais de ensino, podem encontrar oportunidades de aprimorar seus conhecimentos, apesar das razões que antes os impediam de dar seguimento a seus estudos pela modalidade tradicional (presencial) de ensino.

A aprendizagem por toda a vida é essencial e, nesse novo contexto, o ensino de línguas mediado pela tecnologia busca não só superar o isolamento, mas também proporcionar um novo tipo de experiência de aprendizagem na qual o aluno tem a possibilidade de não ser mais sujeito passivo no seu processo de formação.

Para isso, esse aluno deve buscar sua própria motivação, investimento pessoal, autonomia, além de gerenciar seu próprio processo de construção de conhecimento, para que ele possa se tornar agente de sua aprendizagem.

O objetivo deste trabalho é apresentar algumas contribuições da Educação a Distância para a educação continuada de professores de língua estrangeira (inglês) no processo de ensino/aprendizagem de língua estrangeira mediado pela tecnologia.

Com a intenção de conduzir melhor a discussão sobre o tema, acredito ser necessário fazer algumas considerações sobre a fundamentação teórica que norteou a proposição deste trabalho.

\section{Fundamentação teórica}

\section{Entendendo a Educação a Distância}

A Educação a Distância (EAD daqui por diante) tem recebido definições de vários autores. Dohmem (1967, apud NUNES, 1994, p. 4) pontua que a Educação a Distância é uma forma sistematicamente organizada de auto-estudo, onde o aluno se instrui a partir do material de estudo que lhe é apresentado, e onde o acompanhamento e a supervisão do sucesso são levados a cabo por um grupo de professores. Peters (1973, apud NUNES, 1994, p. 4) declara que a Educação/Ensino a Distância é um método racional de partilhar conhecimento, habilidades e atitudes através da aplicação da divisão do trabalho e de 
princípios organizacionais, pelo uso extensivo de meios de comunicação; é uma forma industrializada de ensinar e aprender. Moore (1973, apud NUNES, 1994, p. 4) aborda o Ensino a Distância como a família de métodos instrucionais onde as ações dos professores são executadas à partir das ações dos alunos. Holmberg (1977, apud NUNES, 1994, p. 4) diz que o termo Educação a Distância esconde-se sob várias formas de estudo, nos vários níveis que não estão sob a contínua e imediata supervisão de tutores presentes com seus alunos nas salas de leitura ou no mesmo local. Perry \& Rumble (1987, apud NUNES, 1994, p. 4) afirmam que a característica básica do Ensino a Distância é o estabelecimento de comunicação de dupla via, na medida que professor e aluno não se encontram juntos na mesma sala. Keegan (1991, apud NUNES, 1994, p. 4) afirma que o termo inclui um conjunto de estratégias educativas referenciadas por educação por correspondência, utilizada no Reino Unido; estudo em casa ( home study), na Austrália; Ensino a Distância, na Open University do Reino Unido. Mais recentemente, Paiva (1999, p. 1) define a EAD como

(...) um processo educativo que envolve meios de comunicação capazes de ultrapassar os limites do tempo e espaço e tornar acessível a interação com as fontes de informação e/ou com o sistema educacional de forma a promover a autonomia do aprendiz através de estudo independente e flexível.

Essas são apenas algumas definições para a EAD. Sabe-se, entretanto, que o processo educativo "a distância" é complexo, e, de modo geral, definições dessa modalidade de ensino não conseguem incluir todos os aspectos envolvidos no processo.

Contudo, como as características fundamentais da EAD parecem permanecer basicamente as mesmas, torna-se relevante conhecê-las antes de optarmos por uma definição ou mesmo partirmos para uma nova conceituação.

$\mathrm{Na}$ EAD, aprendizes e professores se encontram separados pelo tempo e/ou espaço. Por isso o processo de comunicação entre eles precisa ser mediatizado, ou seja, os participantes de um curso realizado a distância devem buscar meios que possibilitem a comunicação e a interação entre eles. Esses meios são canais (tecnológicos e humanos) que podem ser correspondência postal e eletrônica, via telefone ou telex, televisão, computador, etc. Por não se encontrarem em um mesmo espaço e, algumas vezes, nem em um mesmo tempo, professor 
e aprendiz necessitam de uma estrutura de organização em que o sistema da EAD esteja atrelado a outros subsistemas integrados, tais como comunicação, tutoria, produção de material didático, entre outros.

É fato que na EAD a aprendizagem se dá de forma independente e individualizada. Todavia, o aprendiz precisa de um esquema de apoio sólido, para que a aprendizagem possa acontecer e para que haja continuidade no processo a que ele se propôs, já que nessa modalidade de ensino considera-se que o aprendiz está mais propenso à desistência.

A auto-aprendizagem é um desafio, pois depende de um esforço individual e contínuo por parte do aprendiz, considerando que a responsibilidade pela aprendizagem passa a ser principalmente dele.

\section{Breve história da EAD como meio de aprendizagem}

Como já mencionado, a Educação a Distância é uma modalidade antiga de ensino. Alves (2001) pontua que a EAD começou no século XV com a invenção da imprensa. De acordo com esse autor, os livros, antes copiados manualmente, eram caríssimos e inacessíveis à plebe, razão pela qual eram lidos por mestres nas escolas. Com a criação da imprensa, tornou-se desnecessário ir às escolas para assistir ao mestre ler. O autor observa, porém, que houve por anos resistência ao livro escolar impresso mecanicamente, o que sem dúvida atrasou o avanço do ensino individualizado, sem a presença física do professor.

Segundo pesquisas realizadas, um dos primeiros marcos da educação a distância foi um anúncio publicado na Gazeta de Boston, no dia 20 de março de 1728, pelo professor de taquigrafia Cauleb Phillip, no qual ele se oferecia para enviar às casas dos interessados lições semanais de sua arte, comprometendo-se a instruir, a distância, as pessoas da região, assim como instruía presencialmente as que viviam em Boston. Posteriormente, foi criada a primeira escola de línguas por correspondência, e, entre outros cursos de semelhante relevância, foi aprovada, em 1891, a organização de cursos por correspondência nos serviços de extensão universitária. Finalmente, em 1898, em Malmoe (Suécia), Hans Hermod, diretor de uma escola que ministrava curso de línguas e cursos comerciais, publicou o primeiro curso por correspondência, dando início ao famoso Instituto Hermod.

De acordo com Perry \& Rumble (1987, apud NUNES, 1994, p. 4-12), nos anos 60, com a institucionalização de várias ações nos campos da 
educação secundária e superior, houve um avanço com relação à educação a distância, começando pela Europa (França e Inglaterra) e se expandindo aos demais continentes. Em nível do ensino secundário: Hermods NKI Skolen, na Suécia; Radio ECCA, nas llhas Canárias; Air Correspondence High School, na Coréia do Sul; Schools of the Air, na Austrália; Telesecundária, no México; e National Extension College, no Reino Unido. Em nível universitário: Open University, no Reino Unido; Fern Universitat, na Alemanha; Indira Gandhi National Open University, na India; Universidade Estatal a Distância, na Costa Rica; Universidade Nacional Aberta, da Venezuela; Universidade Nacional de Educação a Distância, da Espanha; Sistema de Educação a Distância, da Colômbia; Universidade de Athabasca, no Canadá; Universidade para Todos os Homens e as 28 universidades locais por televisão na China Popular, entre muitas outras.

No Brasil há controvérsias com relação aos registros da criação da EAD, o que, de acordo com Alves (2001), dificulta um relato preciso para os estudiosos dessa área.

Em 1939, o Instituto Rádio Monitor foi fundado e, em 1941, o Instituto Universal Brasileiro de formação profissional de nível elementar e médio. A partir daí, foram iniciadas várias experiências, até a criação do MEB (Movimento de Educação de Base), que objetivava alfabetizar milhares de jovens e adultos através das "escolas radiofônicas", principalmente nas regiões Norte e Nordeste do Brasil. O projeto inicial foi desmantelado pela repressão política que se seguiu ao golpe de 1964.

Nos anos 70, em um levantamento feito com o apoio do Ministério da Educação, registraram-se 31 estabelecimentos de ensino utilizando-se da metodologia de EAD, localizados principalmente nos Estados de São Paulo e Rio de Janeiro.

A história da EAD traz como base os materiais escritos, que em geral eram enviados pelo correio, razão pela qual foi identificada a princípio como ensino por correspondência. Em uma segunda fase, mais fortemente na década de 80, passou a incorporar também o uso de tecnologias, tais como o áudio e videocassetes, transmissões de rádio e televisão. O computador apareceu já em uma terceira fase, na década de 90.

Hoje, com a Internet, observamos um crescimento significativo nas instituições de ensino superior com cursos de EAD. Além disso, a Internet está trazendo mudanças também para a educação presencial, 
que tem introduzido situações e técnicas comuns em interações de educação a distância, criando uma aproximação entre as duas modalidades de ensino, o que, sem dúvida, favorece a legitimação definitiva da EAD.

Todos esses fatos amenizam as dificuldades outrora enfrentadas por aqueles que optavam por essa modalidade de ensino, tais como problemas com relação ao envio de material, cumprimento de prazos e solução de dúvidas a curto prazo, entre outros.

$\mathrm{Na}$ verdade, os modelos educacionais tradicionais, há muito tempo, clamam por mudanças significativas no processo ensino/ aprendizagem, e a EAD pode ser uma opção relevante nesse sentido.

Caminha-se para uma flexibilização forte de cursos, tempos, gerenciamento, interação, metodologias, tecnologias, avaliação. Isso obriga a experimentar, pessoal e institucionalmente, modelos de cursos, de aulas, de técnicas, de pesquisa, de comunicação. Todas as universidades e organizações educacionais, em todos os níveis, precisam experimentar formas de integrar o presencial e o virtual, garantindo a aprendizagem significativa. É importante que os núcleos de educação a distância das universidades saiam do seu isolamento e se aproximem dos departamentos e grupos de professores interessados em flexibilizar suas aulas, que facilitem o trânsito entre o presencial e o virtual. (MORAN, 2001, p. 273).

Visto que o reconhecimento da EAD como modalidade de ensino tem se concretizado no processo educativo mundial, redes estrangeiras e brasileiras vêm lentamente se consolidando, contribuindo para a implementação de importantes programas comuns. Atualmente mais de 80 países, nos cinco continentes, adotam a educação a distância em todos os níveis de ensino, em sistemas formais e não formais.

Em 1990, foi criado o CREAD (Consórcio-Rede de Educação a Distância), primeira grande rede de apoio à difusão de experimentos bem sucedidos em EAD no continente americano, com o objetivo de congregar organizações da América do Norte, Central, do Sul e Caribe e aberto também a ligações com outras redes no futuro.

No Brasil, as universidades criaram, em 1989, a READ (Rede Brasileira de Educação Superior Aberta e a Distância), apoiadas pelas instituições de nível superior que já possuíam setores de EAD na época. Entretanto, por falta de apoio governamental, não se registraram mais avanços nessas redes. 
Em 1994, por ocasião do Seminário Internacional de Novas Tecnologias na Educação e na Formação Continuada, foi criado o Brasilead, um consórcio interuniversitário de educação continuada e a distância. Esse consórcio consistia em gerar progamas para aplicação na Rede Teleinformacional nos Ministérios da Educação, das Comunicações, Ciência e Tecnologia e Cultura.

Atualmente contamos com a UniRede. Primeira universidade virtual pública do país, a UniRede nasceu do interesse comum de se fomentar o ensino a distância. Educação pública, gratuita e de qualidade ao alcance de milhões. Formada por um consórcio de 61 instituições públicas de ensino superior (IPES), entre universidades federais, estaduais e CEFETs, a UniRede tem por objetivo democratizar e ampliar o acesso ao ensino superior de alta qualidade e ser um canal privilegiado de capacitação do magistério, através da oferta de cursos a distância nos níveis de graduação, pós-graduação, extensão e educação continuada.

O programa desenvolvido pela UniRede aproveita a infraestrutura e o potencial docente das IPES consorciadas, que produzem cursos em parceria ou isoladamente. A parceria é um modo de racionalizar a utilização dos recursos existentes e garantir a qualidade dos cursos ofertados, uma vez que é nas universidades públicas que se tem o melhor ensino superior do país. A depender das características e objetivos de cada um desses cursos, são utilizadas tecnologias de informação e comunicação específicas como áudio, videoconferência, material impresso, CD ROM e Internet.

Muito se espera do futuro no que se refere à educação a distância e muitas iniciativas têm se concretizado, no sentido de atender a essas expectativas. A EAD é uma realidade que tem se aproximado cada vez mais dos cursos regulares presenciais, até mesmo no sentido de complementá-los, o que ocorre, por exemplo, com os cursos semipresenciais, ou simplesmente no sentido de fazer uso de suas ferramentas como auxiliares na prática pedagógica presencial.

Por essas e outras razões, a EAD deve ser entendida também como aliada da educação presencial, e os participantes dessa modalidade de ensino não devem se sentir marginilizados e isolados do contexto social, pois o que se espera é que, em um futuro próximo, a EAD possa contribuir, mais ainda, para um ensino cada vez mais democrático e motivador. 


\section{A informática e a educação continuada de professores de língua estrangeira (inglês) a distância}

Um dos desafios para a educação continuada de professores de língua estrangeira (inglês) é a adoção de medidas que promovam o desenvolvimento desses profissionais e assegurem a qualidade do ensino/aprendizagem de línguas.

Falar em educação continuada é reconhecer o direito e a necessidade que o homem tem de estudar ao longo de sua vida. Para atender às demandas sociais do mercado, as pessoas estão buscando formas de adaptação que agreguem novos valores. A competição profissional, intensificada com a globalização da economia e com as mudanças culturais e tecnológicas mundiais, tornam a necessidade de uma educação permanente um fato.

Permitir que a educação dos aprendizes fique restrita ao período escolar é impossibilitar a sua atualização profissional e o seu progresso social. Com uma metodologia adequada, os recursos tecnológicos permitem suprir e superar a educação presencial, utilizando-se de meios de comunicação audiovisuais e de informática.

Em 1974, Halliday já considerava o ensino das línguas estrangeiras uma das principais profissões do mundo. Diante de tal afirmação, não se pode ignorar que a EAD, aliada à informática, cria comunidades de aprendizagem de línguas em distâncias potencialmente imensas.

Nesse contexto, o uso da informática possibilita o contato com um largo espectro de informação e conhecimento, e o ensino de línguas mediado pelo computador introduz um novo modelo de ensino/ aprendizagem de língua estrangeira (inglês), cujos desafios envolvem a mudança no papel do profissional, do aluno e das próprias instituições envolvidas.

Sabe-se que, muitas vezes, os alunos que buscam a educação continuada normalmente apresentam um perfil diferenciado. São adultos, trabalhadores que em muitos casos veêm na modalidade de ensino a distância uma opção benéfica. Trata-se, muitas vezes, de alunos que não dispõem de tempo, porque já se ocupam da profissão de professor, mas que necessitam buscar seu auto-aperfeiçoamento.

Como vivemos na era da modernidade e da informação, é exigida do professor essa busca, com vistas a acompanhar seus alunos, que muitas vezes dispõem de mais recursos e de mais tempo que aquele que está mediando sua aprendizagem. 
Segundo Paiva (2001a), os professores deste século precisam estar tecnologicamente alfabetizados para que possam integrar essas novas formas de comunicação ao seu planejamento pedagógico. DIMENSTEIN (Folha de São Paulo, 1997) afirma que o novo papel do professor é o de ser um conselheiro, estimulador de curiosidade e fonte de dicas para proporcionar ao aluno sua própria viagem pelo conhecimento, tanto nos livros como nas redes de computadores.

Ao discutir os saberes necessários ao professor de línguas na atualidade, pesquisadores têm enfatizado que, além dos conhecimentos específicos na área, o profissional deve ter habilidades para resolver problemas, elaborar discussões com clareza, responder rapidamente com soluções originais, ter mente aberta para mudanças e saber usar computador (ALMEIDA FILHO, 2000, p. 35).

Do profissional moderno é exigida a constante renovação de conhecimento e competências. Para essa sociedade que surge, o indivíduo precisa de autonomia, poder de decisão e abertura para as novas e diferentes situações/linguagens que se apresentam, objetivando, assim, acompanhar a velocidade das informações. A memorização, a cópia e a "decoreba" são parte do passado; não é aconselhável ao profissional moderno o apego a regras e hábitos.

A educação continuada de professores constitui uma proposta voltada para a qualificação docente, tendo em vista, através de um trabalho coletivo e reflexivo, oferecer possibilidades para a melhoria em sua prática pedagógica, pelo domínio de conhecimentos/ tecnologias de trabalho.

Popper (2000) observa que o progresso não é uma certeza, mas uma possibilidade. Objetivando se tornar cada vez mais um profissional de qualidade e principalmente fazer parte do mercado de trabalho, o professor deve estar sempre um passo a frente. Através do estímulo à pesquisa, esse profissional pode estar aberto à exploração e à descoberta, enfatizando, assim, sua função re(criadora) sistemática em um universo de características tão diversificadas.

Vale destacar que é fundamental que, desde o princípio da aprendizagem de língua estrangeira a distância, haja um desenvolvimento no sentido de fazer um trabalho que permita aos aprendizes confiar na própria capacidade de aprender e, assim, interagir de forma cooperativa com outros aprendizes e/ou professores. 
Espera-se que o professor deste século seja aquele que faça parte do enredo do desenvolvimento individual e coletivo e que saiba controlar os recursos que a cultura irá indicar como representativos dos modos de viver e de pensar civilizados, específicos dos novos tempos. Para isso, ainda são necessárias muitas pesquisas em novas tecnologias, modelos cognitivos, interações entre pares, aprendizagem cooperativa, adequados ao modelo baseado em tecnologia, que oriente a formação de professores no seu desenvolvimento e ofereça alguns parâmetros para a tarefa docente nessa perspectiva.

A educação continuada de professores pode desempenhar um papel importante na configuração de uma "nova" profissionalização docente, fazendo emergir uma nova cultura profissional e uma cultura organizacional no seio das escolas.

Segundo Nóvoa (1992), cada indivíduo faz parte de um contexto social diferente, portanto, sua formação acontece na medida que estiver pré-disposto a auto-educar-se, auto-aperfeiçoar-se. De acordo com o autor, a formação não se constrói por acumulação de cursos, de conhecimentos ou de técnicas, mas através de um trabalho de reflexividade crítica sobre as práticas e de (re)construção permanente de uma identidade pessoal.

A educação continuada de professores deve proporcionar situações que possibilitem a reflexão e a tomada de consciência das limitações sociais, culturais e ideológicas da própria profissão docente. A formação pode estimular o desenvolvimento profissional dos professores, no quadro de uma autonomia contextualizada da profissão docente. É importante valorizar paradigmas de formação que promovam a preparação de professores reflexivos, que assumam a responsabilidade de seu próprio desenvolvimento profissional.

O ensino de língua estrangeira a distância encontra hoje na tecnologia uma forte aliada, principalmente pelo fato das inúmeras ferramentas desenvolvidas pelas novas tecnologias da informação e comunicação facilitarem o acesso ao ensino/aprendizagem de outros idiomas.

Enquanto a antiga tecnologia utilizava principalmente meios mecânicos e elétricos para cumprir suas funções, a nova tecnologia, de acordo com Hawdrigde (1983), depende mais da eletrônica e compreende três tecnologias convergentes: computação, microeletrônica e 
telecomunicações. Embora também utilizadas pela educação presencial, o uso dessas novas tecnologias na educação a distância tem um efeito relevante.

A informática surge como um recurso de informação extremamente útil e vantajoso na motivação do professor e do aprendiz, além de incentivar a busca de formas de familiarização com a língua estrangeira e construção do conhecimento, tornando o processo de ensino/ aprendizagem de língua estrangeira mais eficaz.

Aliada à informática está a Internet, que vem de encontro às necessidades do mundo moderno. Neste século, professores e aprendizes estão diante de um grande desafio, que é o de preparar e o de ser preparado para a vida e carreira na idade da informação, e a Internet pode auxiliar os aprendizes de língua estrangeira a adquirir habilidades para enfrentar esse desafio.

De acordo com Sachs (1998), a Internet é um espaço gigantesco de intercâmbio e de partilha. Através dela podem-se intercambiar informações, idéias, mensagens eletrônicas, serviços, entre outros. É um espaço de comunicação que reúne pessoas que se encontram por vezes muito afastadas umas das outras no plano geográfico, mas que se aproximam em torno de interesses comuns. Para Weininger (1996), o uso da Internet para fins educativos é quase tão infinito quanto as ramificações da própria rede, e encontra seu limite apenas na imaginação dos professores e alunos que a utilizam.

A educação continuada é facilitada pela possibilidade de integração de várias mídias, que podem ser acessadas síncrona ou assincronamente, isto é, no horário mais favorável a cada indivíduo, e também pela facilidade de contato entre educador e educando. Além disso, o uso da Internet garante uma gama de informações de grande relevância no processo de conhecimento do usuário.

A educação baseada na web $(E B W)$ começou a se popularizar na década de 90 . O termo $E B W$ vem do inglês web-based education e refere-se à utilização de tecnologias baseadas na World Wide Web $(w w w)^{1}$, com o propósito de fomentar o processo educativo e, em particular, a EAD. A www reúne informações em forma de texto, imagens,

${ }^{1}$ Www - World Wide Web, ou Web. Meta-rede, baseada em hipertextos, que integra diversos serviços da Internet, através de uma interface que possibilita o acesso a informações multimídia. 
vídeo e som. A primeira versão da $w w w$ foi colocada na Internet em 1991, mas foi com o lançamento do navegador (browser) Mosaic, em 1993, e o conceito de hipertexto, que o crescimento da web se intensificou (CROSSMAN, 1997; LEVY, 1997, p. 23-24, apud PAIVA, 2001a).

A comunicação mediada pelo computador (CMC) existe desde os anos 60, mas somente nos últimos 10 anos passou a ser amplamente utilizada. Hoje, é vista como uma força poderosa na vida social dos indivíduos, modificando, muitas vezes, princípios e, principalmente, a forma como se processam os relacionamentos offline. De aplicação simples ela causou um profundo impacto no ensino de línguas e, com o surgimento da Internet, abriu dimensões de novos contatos e comunicações antes não possíveis. Professores e alunos de línguas podem se comunicar no momento que considerarem oportuno e fazer uso de inúmeros recursos que possibilitem, além do contato com outros profissionais, acesso a projetos colaborativos, busca de informações, participação em cursos online, criação de sites e periódicos, download, uso de softwares, entre outros. Na $w w w$, professores e aprendizes podem conduzir suas pesquisas com base em material autêntico, colecionar material a ser utilizado em projetos e simulações, obter informações sobre suas aulas e acessar publicações antigas e recentes.

O ensino de línguas mediado pelo computador é chamado CALL (Computer Assisted Language Learning). Nele, o papel do computador pode ser dividido em duas funções principais, tutor e ferramenta, e esse vem se tornando uma das referências básicas para os pesquisadores da área. De um modo geral, o que se vê é um grande crescimento no uso de computadores e, com isso, os professores passaram a se preocupar com seu uso no ensino de línguas, já que tem se tornado cada vez mais relevante nesse contexto.

Entretanto, sabemos que o uso da tecnologia, principalmente a Internet, não se cerca só de vantagens e benefícios. Existem também aspectos negativos, tais como dificuldade em lidar com os recursos tecnológicos, excesso de informação, lentidão no acesso à Rede, alto custo do impulso telefônico (necessário para se ter acesso à Rede), não atualização, má organização ou mesmo desaparecimento de algumas homepages, informações não confiáveis, entre outros. Todos esses aspectos negativos, se não considerados, podem prejudicar os progressos já alcançados, não permitindo que a tecnologia seja explorada em todos os seus recursos com seriedade e confiança. 


\section{Corpus da análise}

O corpus analisado refere-se ao conjunto de perguntas feitas aos aprendizes e aos professores ministrantes do curso através de um questionário. Este trabalho apresenta alguns resultados de uma pesquisa exploratória mais ampla, que ainda se encontra em fase de desenvolvimento. No questionário aplicado aos aprendizes, composto por vinte e seis perguntas estruturadas e abertas, os participantes responderam, por escrito, a questões relevantes ao estudo. O questionário aplicado aos professores é composto por vinte e sete perguntas, também estruturadas e abertas.

Com as respostas desses questionários, objetivava-se obter dados para analisar as contribuições de um curso a distância na educação continuada de professores de língua estrangeira (inglês) e quais os resultados práticos ocorridos em sua vida profissional depois de realizado o curso, na perspectiva dos aprendizes e dos professores ministrantes do curso. Buscou-se, com isso, levantar aspectos positivos e negativos de um curso nesses moldes e como eles podem contribuir com a educação continuada de professores de língua estrangeira (inglês).

As questões visaram detectar se o aprendiz considerou as disciplinas do módulo a distância relevantes para sua formação profissional; se houve alguma transformação significativa em sua vida profissional depois de cursar as duas disciplinas do módulo a distância; se houve preferência, por parte dos aprendizes e professores, entre os dois módulos do curso, já que um era presencial e o outro a distância; se os aprendizes e professores já haviam feito uso de algum recurso tecnológico, com o objetivo de estudo/ministrar aulas, antes de participar do módulo a distância; quais os recursos tecnológicos utilizados durante a realização do módulo a distância e se houve dificuldades em lidar com algum dos recursos tecnológicos; se os aprendizes e professores já tinham participado/ministrado um curso nesses moldes e se eles fariam/ministrariam outro curso como esse; se os aprendizes tinham alguma expectativa com relação a cursos que tivessem módulos realizados a distância antes de fazer esse curso e se sua opinião mudou depois de cursar as duas disciplinas a distância; quais as dificuldades enfrentadas durante a realização do módulo a distância; qual a freqüência do contato entre aprendizes e professores e se a freqüência 
era suficiente; como se dava o contato entre aprendizes/aprendizes, aprendizes/professores e aprendizes/ instituição promotora e se houve interação entre professores e alunos e alunos e alunos; se os aprendizes adquiriram mais autonomia para realizar tarefas e afins; como foi o aproveitamento na opinião dos aprendizes e professores e se algo poderia ser feito para que esse aproveitamento tivesse sido melhor; se houve dificuldades em compreender/orientar as tarefas propostas; se o material didático era específico para o módulo realizado a distância; se houve momentos em que a presença física do professor e colegas era necessária e se houve encontros presenciais durante o curso; quais foram os aspectos positivos e os negativos do curso.

\section{Análise dos dados}

\section{Relevância do módulo a distância para a formação profissional dos aprendizes}

Num primeiro momento, ao serem questionados se consideraram as disciplinas cursadas no módulo a distância relevantes para a sua formação profissional, os aprendizes responderam que sim. Pela resposta unânime desses aprendizes à essa primeira pergunta, percebese que eles não tiveram quaisquer dúvidas ao responder afirmativamente sobre essa relevância, mas somente três participantes, dentre os cinco questionados, destacaram alguma contribuição trazida por esse módulo do curso, como se pode notar pelas declarações abaixo.

Excerto 1:

A: Com a necessidade de se conhecer cada vez mais sobre informática e graças à disponibilidade de computadores em algumas escolas posso afirmar que o curso foi muito útil.

Excerto 2:

B: Considero relevantes pois tive a oportunidade de aprender mais e familiarizar-me com a Internet (...)

Excerto 3:

C: (...) tivemos muitas atividades de pesquisa, principalmente Internet, onde foi possível fazer conexão com o trabalho prático. 
Os outros dois participantes não apresentaram um posicionamento coeso entre a afirmativa da relevância e a justificativa para ela. Embora concordando que as disciplinas cursadas a distância foram relevantes em sua vida profissional, apresentaram respostas pouco elucidativas, deixando transparecer um grau menor de amadurecimento e envolvimento com essas disciplinas do que as outros três participantes citados anteriormente.Um deles mencionou que houve inovações em sua formação, mas sua resposta não apresenta um posicionamento com relação a quais seriam essas inovações. Quanto ao outro, respondeu à pergunta de forma mais limitada ainda, não esclarecendo absolutamente sua afirmativa inicial, como se pode perceber pelas declarações.

Excerto 4:

D: As disciplinas empregadas trouxeram várias inovações que certamente contribuíram satisfatoriamente para a nossa formação enquanto educadoras.

Excerto 5:

E: Porque estavam diretamente ligados à minha prática.

Novos paradigmas estão sendo construídos sobre a educação a distância no Brasil e no mundo. É necessário que os aprendizes que optam por essa modalidade de ensino tenham consciência de suas reais contribuições para o ensino-aprendizagem, para que possam assumir uma postura ativa na sua escolha. Somente a partir da conscientização das necessidades reais de interação interpessoal na educação, do confronto entre o desejado e o factível, independente da tecnologia e com a ajuda da tecnologia, é que se estará contribuindo para o crescimento dessa modalidade de ensino.

\section{Transformações na vida profissional em decorrência do módulo a distância}

Quatro dos cinco aprendizes pontuaram que houve transformações significativas em suas vidas profissionais depois da finalização do curso. Pelas declarações desses participantes, percebe-se que o uso da tecnologia, mais especificamente a Internet, foi o grande destaque do módulo realizado a distância, já que quatro aprendizes citaram o seu uso como o fator de transformação em suas vidas profissionais, o que pode ser comprovado por suas respostas. 


\section{Excerto 6:}

D: Passei a ser aliada da tecnologia pois o curso me convenceu de que o uso da mesma em sala de aula contribui muito com o processo de ensino e aprendizagem.

\section{Excerto 7:}

A: Desenvolvi mais habilidades em relação ao uso da Internet e fiquei a par de uma grande quantidade de exercícios interativos disponíveis na rede, os quais foram usados com meus alunos.

\section{Excerto 8:}

E: Passei a contar com mais uma ferramenta de trabalho: a Internet.

Excerto 9:

C: Através do módulo a distância pude conhecer novas formas de trabalhos, exercícios disponíveis na Internet (...)

O aprendiz que afirmou não ter havido transformações em sua vida profissional se justificou dizendo que não exerce a função de professor, mas que mesmo assim considerou esse módulo muito proveitoso.

Esses depoimentos parecem sinalizar que a evolução e aceitação da informática como meio de comunicação cresce a cada dia, auxiliando como ferramenta interativa satisfatória para a educação a distância. Na EAD, existem recursos tecnológicos suficientes para a troca de informações entre os envolvidos, facilitando a prática desse tipo de pedagogia. O que esta investigação está realçando é justamente a relevância e as facilidades/dificuldades de haver esta prática na EAD.

Na educação presencial, a interatividade professor-aluno-aluno pode ocorrer de maneira mais espontânea. Já na EAD, essa interação parece ter que ser motivada, e o uso da tecnologia, especialmente a informática, pode favorecer essa motivação

A Internet estimula a curiosidade do aluno, possibilita o conhecimento em relação à língua que se está aprendendo, além de fazê-los conhecer sobre essa nova tecnologia de aprendizagem. $\mathrm{O}$ ensino de línguas mediado pela tecnologia ainda é uma forma inovadora no ensino-aprendizagem de língua estrangeira e, como tal, se constitui fonte de discussão para muitos. 
Hoje, com as modernas tecnologias disponíveis, tanto o ensino presencial quanto o ensino semi-presencial ou o ensino a distância, estão passando por um momento revolucionário. As pessoas podem se comunicar mais, motivadas pelas facilidades das tecnologias de comunicação e pelo fato de que esses recursos têm se tornando acessíveis a um número crescente da população.

O mercado profissional está cada vez mais competitivo e a necessidade de educação continuada é crescente. Portanto, os profissionais vão buscá-la onde ela estiver disponível. Sabe-se que no Brasil não há uma distribuição geográfica equilibrada de todos os níveis de educação, nem em quantidade nem em qualidade suficiente. É necessário, então, democratizar o acesso à educação, fornecendo uma educação de qualidade, em todos os níveis, e a EAD pode se tornar uma solução viável e satisfatória para atingir esse objetivo.

\section{Comparação entre o módulo presencial e o módulo a distância}

Três aprendizes tiveram preferência pelo módulo realizado a distância, pois, segundo eles, permitiu a flexibilização do horário e a resolução de dúvidas nos momentos em que elas surgiam, já que podiam mandar "e-mails" a qualquer tempo.

Excerto 10:

D: Tenho preferência pelo módulo a distância, pois pude determinar meu horários para as atividades e em caso de dúvida poderia entrar em contato com os professores e saná-las facilmente.

Excerto 11:

E: O módulo a distância nos permite maior flexibilidade de horário.

Excerto 12:

B: Gostei mais do módulo a distância, apesar de algumas dificuldades (...)

É relevante, entretanto, observar que flexibilização não quer dizer menos tempo gasto para solução de tarefas ou interação professor-alunoaluno, mas a possibilidade de adequar os estudos às outras atividades dos aprendizes. Na educação a distância há a necessidade da disciplina, do aprendizado e do estudo, e por se realizar, praticamente, via escrita, a linguagem deve ser mais elaborada e cuidada, para que os 
participantes possam captar com mais clareza o conteúdo proposto. $\mathrm{Na}$ verdade, o ato de escrever exige mais reflexão, mais comprometimento, mais individualidade, e provoca mesmo certa redundância, quando é necessário reafirmar certos pontos que já haviam sido debatidos anteriormente.

A opinião dos dois professores ministrantes do curso coincide com a dos aprendizes, já que a preferência deles, também, foi pelo módulo realizado a distância. O professor A justificou essa preferência citando problemas que ocorrem comumente nos módulos presenciais, como o atraso às aulas e até mesmo a ausência de alguns alunos. O professor B respondeu que o aproveitamento dos recursos da Internet possibilita uma motivação maior por parte dos alunos.

Excerto 13:

PA: (...) acredito mais nessa metodologia, pois se baseia no construtivismo e não na mera transmissão de informação. O ensino on-line promove a autonomia do aprendiz e incentiva a interação colaborativa.

Excerto 14:

PB: (...) aprendemos das deficiências de módulos anteriores e, com um melhor planejamento e um calendário mais realista, futuros módulos serão mais satisfatórios tanto para o professor quanto para os alunos.

Dois aprendizes, entretanto, alegaram que mesmo com todas essas vantagens, necessitavam do contato físico com professores e colegas, preferindo, dessa maneira, o módulo presencial.

Excerto 15:

C: (...) o módulo presencial proporciona um contato com profissionais da área, que traz grande crescimento e troca de experiências.

Excerto 16

A: Pelo fato de haver maior contato com os professores e colegas, minha preferência é pelo primeiro módulo (presencial).

Essa parte do posicionamento do participante A, entretanto, não está em consonância com o anterior, quando relatou que, através do módulo a distância, pôde conhecer novas formas de trabalho (grifo nosso). O participante parece atentar agora para uma necessidade de 
contato para que ocorra crescimento e troca de experiências. Porém, ao apontar benefícios como esses, citados, também, no módulo a distância, não convence e demonstra fragilidade na sua afirmação. Percebe-se em seu depoimento uma atitude cautelosa, uma dificuldade em romper com o tradicional e em incorporar elementos inovadores.

A interação existente entre todas as pessoas envolvidas num processo educacional, seja ele presencial ou a distância, apresenta vários cenários e atores. A interação professor-aluno ocorre durante as aulas e extraclasse; o mesmo tipo de interação ocorre entre os alunos, que se comunicam durante as aulas e extraclasse. Já que o conteúdo das disciplinas pode ser ministrado aos alunos à distância, satisfatoriamente, utilizando ferramentas adequadas para tal, o diferencial de um curso deste tipo para um curso presencial seria justamente a interação extraclasse. O acesso dos alunos aos professores não acontece espontaneamente, não é possível encontrá-lo em outros lugares. Todos os encontros interativos, síncronos, têm que ser programados, e os assíncronos dependem dos professores acessarem os $e$-mails que são enviados, o que não garante nenhuma certeza de data para as respostas. A comunicação se dá muito mais de forma assíncrona, pois até mesmo a utilização do telefone, de linha ou celular, se torna um pouco mais difícil, devido aos custos de ligação.

\section{Uso de recursos tecnológicos com objetivo de estudos}

Quatro aprendizes já haviam feito uso de recursos tecnológicos com o objetivo de estudar, antes de participarem do módulo a distância. O aprendiz que respondeu não haver feito uso de recursos tecnológicos foi o mesmo que anteriormente se justificou dizendo não ser professor e, apesar de como secretário fazer uso desses, nunca o fez com objetivos de estudo. Os recursos tecnológicos utilizados por eles durante a realização do módulo a distância foram computador, $e$-mail, Internet, disquetes e acesso banda larga.

Duas participantes concordaram que em algum momento tiveram dificuldades em lidar com os recursos tecnológicos mencionados, como se pode notar pelas declarações.

Excerto 17:

A: Compreensão das mensagens dadas na tela do computador quanto aos passos a seguir para, por exemplo, fazer uma homepage. 
Excerto 18:

D: No caso da Internet tive dificuldades em utilizá-la e, por isso, fiquei restrita somente a alguns de seus recursos

Os outros três disseram não terem tido dificuldades. Os professores confirmaram que já faziam uso de recursos tecnológicos com o objetivo de ministrar cursos a distância, antes da realização do curso, citandoos: computador, e-mail, CD-ROM, Internet, disquete, acesso banda larga. E ainda consideraram o domínio do uso desses recursos, por parte de todos os participantes do curso, fundamental para a realização de um curso de educação continuada de professores de língua estrangeira (inglês) a distância. Da sua parte, o professor A considerou não ter havido nenhuma dificuldade durante a realização do módulo a distância. Por parte dos alunos, citou problemas, tais como dúvidas sobre as instruções dos cursos ou do material, mas acrescentou que essas eram facilmente sanadas em seus contatos freqüentes. O professor B considerou ter havido dificuldades para ele no que diz respeito ao calendário de entrega de tarefas, que não foi cumprido inicialmente, havendo um acúmulo de atividades ao final; e, para os alunos, no que diz respeito ao feedback, que poderia ter sido mais eficaz, se houvesse mais tempo para as análises.

Excerto 19:

PA: (...) emails que voltam, problemas de conexão, problemas de software e de configuração que impedem que todos tenham acesso a tudo que é disponibilizado.

Excerto 20:

PB: (...) como prazos para entregar tarefas foram dilatados, calendário não foi cumprido

No ensino mediado pelo computador, o professor necessita conhecer recursos de informática e da Internet para atuar com seus alunos. Ele precisa estar habituado ao uso dos equipamentos, além de buscar conhecer novos métodos e conteúdos, pois assim ele poderá transmiti-los com mais propriedade ao aluno.

Entretanto, mesmo que a Educação a Distância atenda às expectativas de comunicação entre professor-aluno durante as aulas, o uso e, muitas vezes, o custo das tecnologias parecem ser um dos principais motivos que impossibilitam seu uso na freqüência desejada. 
Vivemos em um mundo globalizado, cercado de meios tecnológicos que podem mais excluir do que incluir. Além dos altos custos que o uso da tecnologia, muitas vezes, exige, a adaptação dos aprendizes a ela é lenta, e os pares mais competentes ainda são escassos.

\section{Participação em cursos a distância ou semi-presenciais}

Nenhum dos participantes haviam feito cursos a distância antes. Quatro deles fariam outros cursos nesses moldes, por acreditarem que o aproveitamento é satisfatório, principalmente se comparados a cursos presenciais com uma carga horária muito baixa. Abaixo algumas declarações atestam esse fato.

Excerto 21:

D: Desde que fosse promovido por uma instituição reconhecida. Eu faria novamente, pois acredito que o aproveitamento pode até ser mais satisfatório que um rápido curso presencial.

Excerto 22:

A: Faria, porém apenas se não houvesse outra escolha. Sei que grande parte dos cursos da atualidade envolvem módulo(s) a distância. O que eu quero dizer é que eu não deixaria de fazer um curso só porque ele possui módulo(s) a distância.

Foi destacado, ainda, que o uso da educação a distância poderia inclusive tornar possível a realização de mais cursos no decorrer de suas vidas profissionais, já que três deles estariam dispostos a utilizar todo seu tempo livre para se auto-aperfeiçoarem. Um participante, entretanto, disse não ter mais intenção de fazer cursos nesses moldes, por considerar que a prática oral, a qual ele gostaria de dar mais enfoque, é mais trabalhada em cursos presenciais, como se pode comprovar pela sua declaração.

Excerto 24:

C: (...) hoje penso que seria mais interessante para mim um curso de prática oral.

De acordo com Moran (2001), a educação presencial domina praticamente todas as modalidades de ensino superior. Apesar de se perceber uma abertura a cursos mediados pela tecnologia, sua implantação 
definitiva ainda caminha lentamente. A desconfiança que essa modalidade de ensino ainda gera contribui de maneira decisiva para essa lentidão. Inúmeras são as possibilidades oferecidas pela tecnologia, mas, como citado anteriormente, muitas ainda são desconhecidas e, em algumas situações, ainda inacessíveis. A prática oral, por exemplo, poderia facilmente ser trabalhada em um curso mediado pelo computador, desde que o participante dispusesse de recursos tecnológicos para tal. No entanto, o participante acredita que há limitações nessa modalidade de ensino que impossibilitam essa prática, quando não deveria acreditar, considerando que as possibilidades que a informática oferece são ilimitadas, incluindo a prática oral à que ele se refere.

\section{Expectativas anteriores com relação a cursos a distância ou semi-presenciais}

Todos os aprendizes concordaram que tinham expectativas anteriores com relação a cursos realizados a distância. Essas opiniões variaram muito, desde preocupações com o próprio desempenho, o desempenho e disponibilidade dos professores, a avaliação de seus trabalhos por professores que não viam, a veracidade das tarefas realizadas pelos colegas, até a real validade e seriedade do curso.

Excerto 25:

A: (...) o aluno se sentiria bastante livre para fazer suas tarefas ou mesmo para pedir a outra pessoa que os fizesse para ele.

Excerto 26:

E: (...) uma possibilidade a mais de aprimoramento profissional.

Excerto 27:

D: A minha preocupação era em relação à ausência do professor (...)

Excerto 28:

C: Na verdade esperava menos e me surpreendi com o trabalho realizado pelos professores e pela disponibilidade que os mesmos ofereceram.

Três aprendizes que tinham uma expectativa negativa com relação a cursos realizados a distância mudaram suas opiniões depois de cursar as disciplinas online. Elas destacaram o apoio recebido por parte dos 
professores durante o curso e descobriram-se pesquisadoras, mais seguras de sua própria autonomia, preparadas para fazer uso de recursos tecnológicos e ter voz no seu próprio processo educativo. Dois aprendizes continuaram acreditando no pensamento anterior e não apresentaram maiores justificativas nas suas respostas.

Como já mencionado, a história da EAD não é recente e, apesar de hoje ela estar surgindo com uma roupagem nova e atraente - a tecnologia, a idéia anterior de cursos por correspondência, basicamente cursos técnicos, que o aluno buscava para se profissionalizar, sem compromisso com reconhecimento de orgãos governamentais, mas apenas com o próprio trabalho, ainda é muito forte. Muitos profissionais não têm nem ao menos informações de como muitos cursos de graduação e pós-graduação se processam. É complexo lidar com o desconhecido e, no caso do ensino mediado pela tecnologia, duplamente desconhecido, primeiro por se tratar de um paradigma novo e, segundo, porque os docentes não são visão real, mas apenas mediadores que norteiam o processo a distância.

\section{Contato entre os participantes}

Talvez tenha sido esse o item que mais provocou contovérsia entre professores e alunos e entre alunos e alunos. Dois disseram que o contato não foi freqüente, sendo que um deles relatou que o contato foi mensal e, o outro, que foi semestral.

Excerto 32:

A: No módulo a distância (...) um deles esteve conosco por um dia (...) o outro não teve contato pessoal (...) nós nos conhecíamos porque esteve conosco no módulo presencial.

Excerto 33:

E: Semanal ou quinzenal, dependendo do período.

Ao responderem sobre a razão para a escassa freqüência, esses aprendizes alegaram razões pessoais, tais como a não conexão com a Internet a qualquer tempo e um deles ainda respondeu não ter achado necessário esse contato, já que estava prosseguindo com a realização das tarefas sem maiores dúvidas. Os outros três aprendizes, entretanto, disseram ter mantido um contato semanal ou, pelo menos, todas as 
vezes que realizavam alguma tarefa. Quatro deles consideraram a freqüência suficiente, e o participante que manteve apenas contato semestral não o considerou.

Contradizendo a resposta dos aprendizes, os professores A e B relataram que a freqüência era diária, sendo que o primeiro se manteve em contato diário com os aprendizes até o fim do curso e o segundo, diariamente, até um certo período e, depois, de dois ou três em três dias.

Os aprendizes informaram que o contato entre alunos e professores se dava via e-mail e, em raras situações, por telefone, enquanto o contato entre alunos e alunos se dava por esses meios e também pessoalmente. Três aprendizes disseram ter tido contato com a instituição promotora, por necessitarem utilizar seus computadores. Os dois que podiam utilizá-lo em casa não mantiveram contato com a instituição durante a realização do módulo a distância.

Novamente as opiniões entre aprendizes e professores são divergentes em alguns pontos. O professor A afirmou que o contato entre ele e os aprendizes se deu através de interação via lista de discussão e que entre eles, os professores, não houve nenhum contato, e com a instituição houve, por e-mail. O professor B confirmou o encontro presencial, no início do curso, com os aprendizes, e acrescentou comunicação por $e$-mail individual, além do uso de grupo de discussão. Entre os professores, o professor B considerou que houve uma ocasional troca de idéias quando se encontravam na universidade em que ambos trabalhavam e, com a instituição, um encontro presencial no início do curso.

Acreditamos que essa divergência de opiniões está centrada em diferentes pontos de vista do que seja comunicação em um curso a distância. As afirmações dos aprendizes nos levam a concluir que aprendizes adultos na modalidade on-line tendem a esperar que seus professores/instrutores demonstrem estar "presentes" por meio de um feedback constante e individualizado. É mesmo possível que tal fator seja relativamente mais importante, na perspectiva desses aprendizes, do que o material didático e a tecnologia empregada nos cursos.

As expectativas dos aprendizes podem estar, ainda, centradas no desejo pela aprendizagem individual, ao invés de interagir em comunidades virtuais. Esses aprendizes, muitas vezes, esperam apenas a correção de seus erros. Podem se interessar em participar de comunidades virtuais, sem interagir ativamente, nem esperar o acompanhamento 
docente, algumas vezes preferindo que o professor nem ao menos interfira freqüentemente, nem injete valores e opiniões pessoais nas discussões, ficando apenas responsável por estimular a interação.

\section{A interação no módulo a distância}

Todos os participantes concordaram que houve uma interação satisfatória entre as pessoas envolvidas no curso, e observaram que houve troca de informações e experiências entre eles, principalmente entre os aprendizes, que se sentiam unidos nas dificuldades e sempre se auxiliavam no que podiam.

Excerto 34:

A: Tínhamos acesso (até certo ponto) aos e-mails enviados pelos outros alunos (...)

Excerto 35:

E: A interação se deu de modo eficiente, através de contato por e-mail.

Na opinião de ambos os professores, a interação não ficou comprometida no módulo realizado a distância, coincidindo com a opinião dos aprendizes.

Pierre Lévy (1999, p.158) pontua que

A EAD explora certas técnicas de ensino a distância, incluindo a hipermídia, as redes de comunicação interativas e todas as tecnologias intelectuais da cibercultura. Mas o essencial se encontra em um novo estilo de pedagogia, que favorece ao mesmo tempo as aprendizagens personalizadas e a aprendizagem coletiva em rede.

Nesse contexto, o professor é incentivado a tornar-se um animador da inteligência coletiva de seus grupos de alunos, em vez de um fornecedor direto de conhecimentos.

A interação implica na comunicação recíproca, no intercâmbio de informações e na compreensão do outro. O processo de aprendizagem mediado pela interação vai levar à construção de um conhecimento conjunto entre aluno-professor-aluno. Nesse contexto, a comunicação será caracterizada pela interação entre aprendizes, e parceiros mais competentes podem auxiliá-los no seu aprendizado.

Existem, entretanto, fatores que dificultam a interação entre os envolvidos em um curso a distância, tais como a falta de domínio satisfatório no uso das ferramentas tecnológicas disponíveis. Pelas 
declarações dos aprendizes, comprovamos que isso ocorreu durante o curso. Outros fatores são a falta de interesse do professor, seguida da falta de interesse do aluno, o que, pelas afirmações, não ocorreu, nesse curso especificamente; e, além da dificuldade de acesso, o custo das tecnologias, percebido como obstáculo durante a realização do módulo a distância.

Para que um curso a distância se realize com sucesso é necessário que ocorra a interação, nem que seja do aprendiz com o próprio material didático utilizado, o que não é difícil, já que todo ou parte dele estará na rede. No curso, especificamente de acordo com a opinião do professor A, a interação ocorreu mais com o material do que com o professor propriamente dito.

\section{Excerto 36:}

PA: A interação foi mais com o material do que com o professor (...)

Na opinião do professor B, a interação independe da modalidade, diferindo da opinião do aprendiz E, que declarou que a interação se deu de modo eficiente no módulo a distância, e que nos levou a concluir que ele intencionou declará-la mais eficiente do que no módulo presencial, já que foi o único fato que ele mencionou com relação à interação.

\section{Autonomia}

Os participantes, e, também, os professores concordaram ainda que os aprendizes adquiriram mais autonomia no módulo a distância, pois, segundo eles, tinham mais tempo para a solução de tarefas. Por se tratar de um estudo individualizado, precisavam "ousar" mais, além de terem que acreditar mais na própria competência, já que nem sempre podiam compartilhar suas dúvidas.

Excerto 37:

D: Me sentia muito a vontade respondendo às questões com tranqüilidade em casa e com bastante tempo.

Excerto 38:

A: Adquiri maior autonomia porque se quisesse tirar alguma dúvida imediatamente e a máquina não a sanasse eu teria que recorrer aos meus próprios recursos. 
Excerto 39:

E: Porque no módulo a distância, fui estimulada, ou mesmo impelida a realizar as tarefas por conta própria, porque na maioria das vezes o contato imediato com o professor não era possível.

A grande contribuição adquirida pelos aprendizes nesse curso parece ter sido o ganho de maior autonomia por parte deles. O próprio fato de responder às perguntas abertas, tentando e, na maioria das vezes, conseguindo expor opiniões e conceitos, demonstra que a maioria desses aprendizes, que revelou nunca ter feito um curso nesses moldes anteriormente, passou a conhecer o projeto no qual se inseriu e se posicionou com relação a ele, o que demonstra autonomia. Só podemos exercer a autonomia se tivermos um compromisso éticoprofissional. A aprendizagem é uma conseqüência desse compromisso, pois só se aprende quando se quer e quando se esforça para tal. A autonomia precisa ser construída em bases sólidas e, sobretudo, precisa ser exercitada. Ao adquiri-la, o aprendiz se apropria do conhecimento, refletindo criticamente sobre seu próprio aprendizado, tornando-o, assim, mais eficaz.

\section{Algumas especificidades próprias de um curso realizado a distância}

Três participantes classificaram o aproveitamento no curso como "bom", uma o considerou "muito bom" e outra, como "regular". Ambos os professores declararam que o aproveitamento do curso por parte dos aprendizes foi bom e o consideraram dentro das expectativas. Três aprendizes concordaram que nada poderia ser feito para que o aproveitamento tivesse sido melhor. Um deles, entretanto, se responsabilizou, em parte, respondendo que se tivesse se dedicado mais, buscado mais contato e troca de idéias com os colegas, teria obtido um retorno maior, além de ter sentido falta também de uma maior disponibilidade por parte dos professores.

Excerto 40:

A: Maior dedicação por minha parte. Mais contato e troca de idéias com os colegas. Disponibilidade de orientadores quanto ao manejo da Internet também ajudaria muito. 
O outro participante acredita que sua atuação teria sido melhor se o acesso às tecnologias necessárias ao módulo tivesse sido maior.

\section{Excerto 41:}

D: Se eu tivesse maior acesso às tecnologias empregadas durante o curso talvez poderia ter tido resultados melhores.

Os aprendizes aqui parecem divididos, um grupo se eximindo da responsabilidade no que diz respeito à sua atuação durante o módulo realizado a distância, quando sabemos que há sempre uma possibilidade de melhora e algo a ser feito quando não se conceituou seu próprio fazer como o melhor, e o outro grupo, mais consciente de suas próprias falhas e das falhas da própria organização do curso, que era um curso, como já dito, experimental e, portanto, sujeito a problemas.

No que diz respeito ao material didático, a informação dos participantes é de que se tratava de um material específico para a disciplina a distância, e não apenas de um material transposto do impresso para o virtual. Quatro aprendizes o consideraram "bom" e um deles o considerou "regular".

Os professores confirmaram a declaração dos aprendizes com relação à especificidade do material didático e fizeram observações acerca da diferença desse material para um produzido para um curso presencial.

Excerto 42:

PA: A construção da homepage e o detalhamento de cada atividade.

Excerto 43:

PB: Há especificidades em um material produzido para curso a distância. Ele utiliza links já existentes na web que disponibilizam som e imagem (material multimídia).

O material didático é elemento fundamental na realização de um curso, sobretudo se se tratar de um curso a distância. O aprendiz interage com o material e é através dele que se comunica com os outros participantes. Ele é base para todas as atividades, e é através dele que o aprendiz se orienta, no sentido de avançar e concluir as atividades propostas. 


\section{Ausência física}

Três aprendizes disseram sentir falta da presença física do professor e dois disseram não sentir. Com relação à ausência física de colegas, quatro afirmaram ser esse o maior defeito de cursos a distância, pois sentiam falta da troca de idéias, do contato extraclasse e do companheirismo que surge quando se convive pessoalmente.

Excerto 44:

A: (...) houve vezes em que eu não entendia o que a mensagem da tela estava me pedindo, pois não tenho um bom conhecimento de computação.

Dois deles afirmaram não sentir falta, por considerarem o contato virtual mais objetivo, como se pode comprovar pela declaração de um deles.

Excerto 45:

D: Qualquer dúvida poderia ser retirada a partir do contato que mantínhamos com eles.

A não visão física dos participantes parece ainda ser uma das grandes reclamações por parte de aprendizes que optam pela modalidade de ensino a distância. A presença física parece garantir segurança de sucesso na aprendizagem, como se alguém pudesse ser responsabilizado pela aprendizagem de outrem. As pessoas precisam se conscientizar que no ensino/aprendizagem, de modo geral, o que deve ocorrer é uma orientação e, em alguns casos, até uma influência de pares mais competentes. No ensino aprendizagem de línguas, o conhecimento é adquirido de forma espontânea e, portanto, imprevisível. O aprendiz precisa buscar sua própria forma de entendimento para que a aprendizagem ocorra de fato.

\section{Vantagens e desvantagens do módulo realizado a distância}

Os participantes consideraram como as maiores vantagens do curso a flexibilidade do horário, o aprimoramento do uso de tecnologia, a facilidade de interação, a crescente busca da autonomia, a possibilidade de ser mais criativo, o incentivo à pesquisa e, ainda, a troca de experiências com os colegas e outros "colegas" virtuais. Com relação 
às desvantagens, citaram o pouco uso oral da língua e a dificuldade em lidar com a tecnologia, mais especificamente a informática.

Sobre os aspectos positivos e/ou negativos do módulo que foi realizado a distância, o professor A citou como aspectos positivos a assincronia, que permitia que cada aluno trabalhasse no horário que preferisse, obedecendo o próprio ritmo, e a autonomia, pois em sua opinião, o professor não estando presente, apesar de acessível, impulsiona o aluno a fazer mais tentativas, a experimentar mais antes de recorrer a ele. $\mathrm{Na}$ opinião do professor $\mathrm{B}$, os aspectos positivos foram a elasticidade do tempo para absorção dos conteúdos e a utilização de tecnologia. A opinião do professor B coincide com a opinião dos aprendizes que ressaltaram a relevância desse contato com a tecnologia e também a questão do tempo maior para a solução de tarefas. No que diz respeito aos aspectos negativos, foram citados pelo professor A problemas com emails que voltavam, com a conexão, com o software e de configuração, que impediam que os alunos tivessem acesso a tudo que era disponibilizado. O professor B citou problemas como prazos para entrega de trabalhos, que foram dilatados, prejudicando o cumprimento do calendário, idealizado a princípio.

Nenhuma modalidade de ensino, seja ela presencial ou a distância, está fadada só ao sucesso ou só ao fracasso. O que deve ser pontuado é que ambas existem e dividem espaço entre opiniões de aprendizes e professores.

As vantagens do meio virtual são reais e cada vez mais estão ocupando espaço no ensino tradicional. O mundo, evolui a cada dia e é nossa obrigação evoluir junto com ele. Isso não implica forçar preferências, mas aceitar as inovações e fazer uso positivo delas se necessário. Não podemos fechar os olhos à modernidade, ela está aí para ser usufruída e se não nos propusermos pelo menos a conhecêla, corremos o risco de nos tornarmos absoletos sem nem ao menos ter tido a chance de fazer essa escolha.

\section{Conclusão}

As informações acima nos levam a inferir que a educação continuada de professores de língua estrangeira a distância ainda tem um longo caminho a percorrer. 
A questão principal ao se aplicarem os questionários aos professores e aprendizes era saber se, na opinião deles, as disciplinas ministradas a distância foram relevantes para o curso em si, se atenderam às expectativas de atualização profissional daqueles discentes, e se os professores se convenceram de que os participantes estavam preparados, de fato, para o uso da tecnologia no processo pedagógico. Mais ainda, saber se há possibilidade de demanda por cursos a distância, ou semi-presenciais como esse, via Internet, se a infra-estrutura tecnológica disponível possibilita o desenvolvimento de cursos a distância e se as ferramentas (serviços) da Internet possibilitam a realização de cursos interativos.

A educação a distância, tendo como mediadora a tecnologia, na educação continuada dos professores de língua estrangeira (inglês) foi viável, nesse curso especificamente e, ao mesmo tempo, atendeu às expectativas daqueles professores/aprendizes?

Com base nos dados levantados nesses questionários, foi possível perceber que os professores investigados acreditam mais nessa metodologia de ensino do que na tradicional, porque acreditam que as expectativas daqueles profissionais quanto ao curso a distância, apoiado na tecnologia, mais especificamente na Internet, foram atendidas, ainda que não em sua plenitude, devido ao seu caráter experimental, mas gerando um bom nível de satisfação pessoal com os resultados alcançados por cada um.

Também, foi obtida a convicção que os aprendizes são capazes de interagir e obter autonomia nas realizações de trabalhos via Internet. A demanda parece ser uma possibilidade, já que essa modalidade de ensino tem condições de atender aos anseios daquele profissional, ao mesmo tempo que viabiliza a determinação legal contida na LDB e cumpre seu papel social de incentivar o oferecimento de disciplinas através do ensino não-presencial, como forma de disseminar informações, sem deixar de estimular a auto-aprendizagem.

Sabe-se que a EAD não é uma modalidade de ensino baseada somente no uso da tecnologia, especialmente da Internet, justamente pelo fato dos equipamentos e tecnologia ainda não estarem acessíveis a grande maioria das pessoas, mas não se deve, entretanto, ignorar ou desprezar o seu uso, pois as vantagens e facilidades que o uso da tecnologia na educação proporciona são relativamente superiores às 
dificuldades a serem enfrentadas para adquiri-la. Particularmente, no Brasil, onde o grande problema social está diretamente relacionado com a falta de educação de enorme parte de sua população, esse tipo de ensino pode se tornar de extrema valia e importância no processo educacional.

Com o avanço da World Wide Web e a utilização de sons, imagens, efeitos e vídeos, associada ao atual avanço das redes de comunicações e uso de tecnologias mais sofisticadas, a informação multimídia chegará em qualquer lugar do planeta, tornando o ciberespaço uma fonte inesgotável de conhecimento e educação. A EAD, fundamentada na concepção de um material didático bem estruturado, bem elaborado e que utiliza recurso de comunicação capaz de substituir a educação "face-a- face", é fator de motivação no autoaprendizado.

Contudo, a EAD não deve ser vista como uma prática de ensinoaprendizagem substituta da forma presencial. Observando-se as limitações e as falhas do sistema educacional convencional, pode-se concluir que, pelas próprias características e objetivos da EAD, ela pode vir a complementar e, ao mesmo tempo, coexistir, paralelamente, apoiando o ensino tradicional. Vale ressaltar que o crescimento do ser humano se dá principalmente através da educação, seja ela presencial ou a distância, e o que puder ser feito para agilizar e facilitar a chegada desse conhecimento será bem-vindo e tem de ser prestigiado. A educação mediada pela tecnologia pode, sem dúvida, educar, aproximar distâncias, facilitar a vida do aluno e disseminar o ensino aos cantos mais remotos do planeta, sendo uma iniciativa muito válida e que deve ser experimentada.

\section{Referências Bibliográficas}

ALMEIDA FILHO, J.C.P. Crise, transições e mudança no currículo de formação de professores de línguas. In: FORTKAMP, M. B. M.; TOMITCH, L. M. B. (Org.). Aspectos da lingüistica aplicada: estudos em homenagem ao professor Hilário Inácio Bohn. Florianópolis: Editora Insular, 2000. p. 33-47.

ALVES, J. R. M. Educação a distância e as novas tecnologias de informação e aprendizagem. 2001. Disponível em: <http://www.engenheiro2001.org.br/ programas/980201a1html>. Acesso em: 20 set. 2003 
CROSSMAN, D. M. The evolution of the world wide web as an emerging instructional technology tool. In: KHAN, B. H. New Jersey: Educational Technology Publications, 1997. cap. 2, p. 19-24.

DIMENSTEIN, G. Computadores redefinem novo analfabeto. Folha de São Paulo, São Paulo, 25 maio 1997.

HALLIDAY, M.A.K. et al. As ciências lingüisticas e o ensino de linguas. Petrópolis: Vozes, 1974. Cap. 7, p. 7-164.

HAWKRIDGE, D. New information technology in education. Baltimore: The Johns Hopkins University Press, 1983. 238 p.

LEVY, P. O que é virtual? 3. ed. São Paulo: Editora 34, 1999. 157 p.

LEVY, P. Cibercultura. 2. ed. Trad. Carlos Irineu da Costa. São Paulo: Editora 34, 1997. 260 p.

MORAN COSTAS, J. M.; MASETTO, M.; BEHRENS, M. Novas tecnologias e mediação pedagógica. 3. ed. Campinas: Papirus, 2001. Disponível em: $<$ http://www.eca.usp.br/prof/moran/textosead.html.> Acesso em 20 jul. 2003.

MORAN, Josá Manuel. Novos desafios na educação - a Internet na educação presencial e virtual. Saberes e linguagens de educação e comunicação, Pelotas, v. 1, p.19-44, set. 2001. Disponível em: < http:// www.eca.usp.br/prof/moran/textos.htm>. Acesso em: 3 out. 2003.

NÓVOA, A. (Org.). Os professores e a sua formação. 2n ed. Lisboa: Publicações Dom Quixote, 1992. 158 p.

NUNES, Ivônio B. Noções de educação a distância. Revista Educação a Distância, Brasília, Instituto Nacional de Educação a Distância, n. 4/5, p. 7-25, dez. 1993-abr. 1994. Disponível em: http://www.ibase.org.br/ ined/ivoniol.html. Acesso em: 25 fev. 2003.

PAIVA, V. L. M. de. O papel da educação a distância na política de ensino de línguas. In: MENDES, Eliana et ali. (Org.) Revisitações: edição comemorativa: 30 anos da Faculdade de Letras/UFMG. Belo Horizonte: UFMG/FALE, 1999.

PAIVA, V. L. M. de. A www e o ensino de inglês. Revista Brasileira de Lingüistica Aplicada, Belo Horizonte: Faculdade de Letras da UFMG, v. 1, n. 1, p. 93-116, 2001a.

PAIVA, V. L. M. de. Interação e aprendizagem em ambiente virtual. Belo Horizonte: Faculdade de Letras, UFMG, 2001b. 334 p. (Estudos Lingüísticos 1). 
PERRY, W.; RUMBLE, G. 1987. A short guide to distance education. In: NUNES, Ivônio B. Noções de educação a distância. 1992. Disponível em: http://ibase.org.br/ ined/ivonio.html. Acesso em: 27 jul. 2003.

POPPER, F.R. O historicismo e sua miséria. São Paulo: Cultrix, 2000. p. 60. SACHS, F. La défense de la Francophonie et de la Langue Française sur Internet. Mémoire de DEA de Didactologie des Langues et des Cultures. Université Paris III, 1998.

WEININGER, M. J. O uso da internet para fins educativos. 1996. Disponível em: <http://www.cce.ufsc.br/lle/alemao/markus/internet.html.> Acesso em 23 ago. 2001. 